NASA Technical Memorandum 100408

\title{
The Value of Early Flight Evaluation of Propulsion Concepts Using the NASA F-15 Research Airplane
}

Frank W. Burcham, Jr., and Ronald J. Ray

(MASA-TH-100408) THE VALOE CF EABLY FLIGHT EVALUATIO OP PROPOLSICA COUCETIS OSIHG THE MASA P-15 RESEABCE IIERLABE (MSA) $15 \mathrm{p}$ Avail: IIS BC A02/AF A01 CSCL 21E
187-26913

Dnclas 63/07 0093403 
NASA Technical Memorandum 100408

\section{The Value of Early Flight Evaluation of Propulsion Concepts Using the NASA F-15 Research Airplane}

Frank W. Burcham, Jr., and Ronald J. Ray

Ames Research Center, Dryden Flight Research Facility, Edwards, California

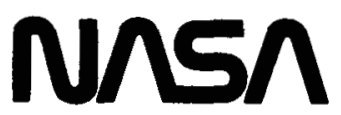

National Aeronautics and

Space Administration

Ames Research Center

Dryden Flight Research Facility

Edwards, California 93523-5000 
THE VALUE OF EARLY FLIGHT EVALUATION OF PROPULSION CONCEPTS USING THE MASA F-15 RESEARCH AIRPLANE

\author{
Frank W. Burcham, Jr.* and Ronald J. Ray** \\ NASA Ames Research Center \\ Dryden Flight Research Facility \\ Edwards, California
}

\section{Abstract}

The value of early flight evaluation of propulsion and propulsion control concepts was demonstrated on the NASA F - 15 airplane in programs such as highly integrated digital electronic control (HIDEC), the F100 engine model derivative (EMO), and digital electronic engine control (DEEC). (In each case, the value of flight demonstration was conclusively demonstrated.) This paper describes these programs, and discusses the results that were not expected, based on ground test or analytical prediction. The role of flight demonstration in facilitating transfer of technology from the laboratory to operational airplanes is discussed.

\section{Nomencl ature}

ADECS adaptive engine control system

AEDC Arnold Engineering and Development Center

A

CAS

jet primary nozzle area, $f t^{2}$

CENC

control augmentation system

CIVV convergent exhaust nozzle control

DEEC compressor inlet variable vane

DEFCS digital electronic engine control

EMD digital electronic flight control system

EPR

FDA

FTIT

HIOEC engine model derivative engine pressure ratio, PT GM/PT2 fault detection and accommodation fan turbine inlet temperature, ${ }^{\circ} \mathrm{F}$

HP

highly integrated digital electronic control

HP pressure altitude, $\mathrm{ft}$

LOD light-off detector

M Mach number

NI fan rotor speed, rpm

N2 core rotor speed, rpm

$P A B$ augmentor static pressure, $1 \mathrm{~b} / \mathrm{in}^{2}$

*Assistant Chief, Vehicle Technology Branch. Associate AIAÁ Fellow.

**Aerospace Engineer. Member AIAA.
PB

PLA

PS2

PT2

PTOM

RCVY

SEC

TT2

VC

WA

WF

WFAB

WFGG

$\alpha$

B

$\Delta$

\section{Introduction}

The operation and control of the propulsion system of a high-performance fighter airplane is critical to its success. The NASA Ames Research Center Dryden Flight Research Facility (AmesDryden) has been conducting flight research using an F-15 airplane for several years.1 Much of this research has been concerned with propulsion, propulsion control, and integrated propulsion-flight controls. The early flight evaluation of a new propulsion concept has been quite beneficial, both in terms of timely exposure of problems and in facilitating technology transfer from laboratory to production. Examples of timely flight evaluations conducted on the F-15 include a digital engine control system, an advanced derivative engine, and an integrated propulsion-flight control system.

In the first flight experiment, a prototype digital electronic engine control (DEEC) was tested.? The DEEC provides a full-authority digital control capability for the $F 100$ engine in the F-15 atrplane, and results in significant performance and operability improvements. As a followon program to the DEEC evaluation, the F100 engine model derivative (EMD) was also flown in the $F-15$ 
airplane. 3 The F100 EMD engine incorporates a new fan design, improved hot section materials, and has 15 percent more thrust than the standard F100 engine. With the experience derived from the DEEC and EMD evaluations, Ames-Dryden, in cooperation with other government agencies, is conducting a program called highly integrated digital electronic control (HIDEC).4 This program developed and evaluated new digital engine control technology that is integrated with the airplane digital flight control system. This report discusses the propulsion flight evaluations conducted on the F-15 airplane on the DEEC, EMD, and HIDEC prograns, and the significant contribution of early flight evaluation to these emerging technologies.

\section{Description of Equipment}

\section{Airplane}

The NASA F -15 airplane (Fig. 1) used for the DEEC, EMD, and HIOEC programs is a highperformance, air-superiority fighter aircraft with excellent transonic maneuverability and a maximum Mach capability of 2.5. It is powered by two afterburning turbofan engines.

Engine

The $F 100$ engine (Fig. 2) used in the DEEC, EMD, and HIDEC programs, is a low-bypass-ratio, twin-spool, afterburning turbofan engine. The three-stage fan is driven by a two-stage, lowpressure turbine. The 10-stage, high-pressure compressor is driven by a two-stage turbine. The engine incorporates compressor inlet variable vanes (CIVV) and rear compressor variable vanes (RCVV) to achieve high performance over a wide range of power settings; a compressor bleed is used only for starting. Continuously variable thrust augmentation is provided by a mixed flow afterburner and a variable area convergent divergent nozzle.

For the DEEC program, the F100-PW-100 engine was used. This engine is the production engine for F-15 and F-16 airplanes. It incorporated a five-segment augmentor, a prototype DEEC system, and a fan inlet static pressure (PS2) probe on the engine hub.

The F100 EMD (Company designation PW1128) is d derivative of the $\mathrm{F} 100-\mathrm{PW}-100$; it incorporates a redesigned higher airflow and pressure ratio fan, improved materials in the hot section, a redesigned 16-segment augmentor, and a latergeneration $D E E C$, resulting in an average thrust increase of 15 percent. The F100 EMD engines have also been used in the HIDEC program.

Digital Electronic Engine Control System.

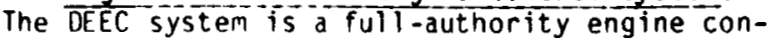
trol system for the $F 100$ engine. It controls the eight major controlled variables on the engine and replaces the standard $F 100$ engine hydromechanical unified fuel control and supervisory digital electronic engine control. The DEEC is enginemounted, and fuel-cooled, and consists of a singlechannel digital controller with selective input output redundancy, and a simple hydromechanical secondary engine control (SEC).
Since the DEEC provides key technology for all three projects discussed in this report, an outline of the DEEC system is presented here. More details may be found in Ref. 2. The DEEC system consists of three units, functionally illustrated in Fig. 3, which shows the DEEC electronic unit, the gas generator fuel metering valve and SEC unit, and the augmentor fuel metering and segment sequencing unit. The DEEC receives inputs from the airframe through the throttle position, power lever angle (PLA), and Mach number (M) and from the engine through pressure sensors (fan inlet static pressure (PS2), burner pressure (PB), and turbine discharge pressure (PTGM)), temperature sensors (fan inlet total temperature (TT2) and fan turbine inlet temperature (FTIT)), fan rotor speed sensors (N1) and core rotor speed sensors (N2), and the ultraviolet flame sensor (the light-off detector (LOD)). It also receives feedback from controlled variables through position feedback transducers indicating variable vane (CIVV and RCVV) positions, metering valve positions for gas generator fuel flow (WFGG), augmentor fuel flow (WFAB), augmentor segment-sequence valve position, and jet primary nozzle area position (AJ). Dual sensors and position transducers are used, as shown in Fig. 3, to achieve redundancy in key parameters. The input information is processed by the DEEC computer to schedule variable vanes CIVV and RCVV, position the compressor start bleeds, control gas generator and augmentor fuel flows, position the augmentor segment sequence valve, and control the exhaust nozzle area. Redundant coils are present in the torque motor drivers for all of the actuators.

The DEEC logic provides open-loop scheduling of the CIVV, RCVV, start bleed position, and augmentor controls. The DEEC incorporates closedloop control of airflow (WA) and engine pressure ratio (EPR). The closed-loop logic el iminates the need for periodic trimming and improves performance. The two main control loops are shown in Fig. 4. The upper part of the figure shows the airflow logic in wich WFGG is controlled to maintain the scheduled fan speed, and hence, airflow. Proportional-plus-integral control is used to match the $N 1$ request to the sensed $N 1$. Limits of N2, FTIT, and PB are maintained. Shown in the lower part of Fig. 4 is the engine pressure ratio (EPR) loop. The requested EPR is compared with the measured EPR, based on fan inlet total pressure (PT2) and PTGM; using proportional-plusintegral control, the nozzle is modulated to achieve the requested EPR. The EPR control loop is only active for intermediate power operation and augmentation. At lower power settings, a scheduled nozzle area is used.

With the closed-loop airflow and EPR logic, the DEEC control is capable of automatically compensating for engine degradation. EPR is directly related to thrust, so the DEEC can maintain an engine at a desired thrust level, eliminating the trimming requirement. As the engine degrades, the FTIT required to achieve the scheduled EPR increases until it reaches its limit. The DEEC then operates the engine on the FTIT limit.

The PT2 signal is derived from the PS2 measurement. A PT2-PS2 relationship has been determined from previous wind-tunnel and flight tests. 
Augmentor Logic. Augmentor segment fuel distribution is handled by augmentor fuel metering and segment sequencing valves (Fig. 3 ). The fivesegment augmentor used in the DEEC tests has two metering values: one for the core segments, and one for the duct segments. The logic provided for "quick fill" and segment limiting is described in detall in Ref. 2. For the 16-segment augmentor used in the F100 EMD tests, a single fuel metering valve was provided, and no quick fill was used. Logic was incorporated to prevent rumble (a combustion-acoustic coupling disturbance) and to maintain the augmentor durability. For the latter part of the DEEC evaluation, and for the F100 EMD flight evaluation, a light-off detector (LOD) was installed. This ultraviolet sensor had an output that was proportional to flame intensity (LOD counts). With the LOD, logic was incorporated to automatically detect augmentor blowouts and attempt relights without pilot action (PLA recycles).

Fault Detection and Accommodation (FDA) Logic. The DEEC system is a single-channel digital controller with selective redundancy in the inputs and outputs to maintain digital control of the gas yenerator for any single input-output failure. The pressure sensors are not redundant; in the event of loss of a pressure sensor, a synthesized value is calculated. If digital control cannot be maintained, control is automatically transferred to the secondary control (SEC). The FDA logic is described in detail in Ref. 5 .

Secondary Control. The SEC in the DEEC system (Fig. 3) is a simple hydromechanical engine control housed in the same unit as the DEEC gas generator fuel-metering valves.6. The SEC provides control of WFGG, compressor start bleed, and RCVV as functions of PLA, PS2, and TT2. The SEC operation is limited to nonaugmented power and is operable, at a reduced performance level, over the entire engine operating envelope. There is an open-loop airstart capability during SEC operation. The SEC operation is selected automatically by the DEEC if digital control cannot be maintained; it inay also be selected by the pilot.

\section{Flight Control System}

The $F-15$ is normally equipped with a mechanical flight control system and an analog control augmentation system (CAS). For the HIDEC tests, the analog CAS was replaced with a digital electronic flight control system (DEFCS). This system duplicated the analog CAS functions and al so had excess capacity which was used for integrated propulsion and flight control. The DEFCS is a dual-channel fail-off system, programmed in PASCAL. It has a MILSTO $1553 \mathrm{~A}$ data bus interface and is described in more detail in Ref. 4.

Instrumentation

The F-15 airplane is equipped with a data systein that records information from the engine and airplane instrumentation. In excess of 400 parameters were typically measured on the test engine, consisting of pressures, temperatures, rotor speeds, fuel flows, and digital data from the DEEC. These data were digitized and recorded onboard and al so telemetered to the ground for real-time display and computation.

\section{Results and Discussion}

Results of the DEEC Flight Evaluation

The DEEC flight evaluation consisted of five phases flown over 5 years. The cases in which significant differences between expected and actual results were found are discussed in the following sections.

FDA Testing. The DEEC design philosophy, single channel digital with dissimilar hydromechanical backup, is of interest from a reliability and fault accommodation capability perspective. Extensive testing was performed on the FDA logic operation and its ability to transfer to SEC under selected failure conditions. The initial tests were performed with an engine digital simulation. A later closed-loop bench test allowed hydromechanical and electronic components to be run while operating with the engine computer simulation. This allowed testing of the FDA by intentionally introducing faults into the system without the risk of damaging an engine. Additional testing included sea-level and altitude tests of selected failures and the resulting accommodation process. During the course of the initial NASA DEEC flight test program, only two failures occurred. These were correctly detected and accommodated. The first was a detected failure of the fan inlet total temperature (TT2) sensor, which resulted in the use of the redundant sensor and no loss in performance. The second failure involved the PTOM sensor, causing the nozzle trim and augmentation to be inhibited wile DEEC engine control was maintained. There were no false failures detected by the DEEC and no required transfers to the SEC mode because of control system anomalies.

Because only two faults occurred in the initial DEEC flight evaluation on the NASA F - 15 airplane, it was not possible to adequately evaluate the DEEC system operation in the synthesized parameter modes. Therefore, an additional DEEC flight investigation was conducted in which certain sensors were failed in-flight. 7 This allowed the failure detection logic to be evaluated and permitted operation in the synthesized parameter modes at various points in the flight envelope (Fig. 5). Once in the synthesized parameter mode, the DEEC system operation was excellent. Pilots could often not tell that the engine was operating with synthesized parameters. There were, however, some problems encountered with fault detection. 7 Some of these problems were a result of the DEEC FDA design philosophy. The FDA tests identified several problems that have since been corrected, including one software scaling error. Overall, the FDA testing was quite helpful, and the inflight FDA concept was validated.

Following the NASA tests, the DEEC system was installed on several F-15 airplanes in the USAF training operations at Nellis AFB. Experience showed that reliability and maintainability were greatly improved, mean time between failures was improved by a factor of two, and unscheduled engine 
removals were reduced by a factor of nine. Much of this improvement is due to the DEEC FDA which successfully detects and accommodates failures.

Nozzle Instability. Another area of interest is the stability of the EPR control loop. This loop is used in the HIDEC program to vary the stall margin in response to airplane maneuvers. During the DEEC program, an unexpected nozzle instability was encountered that revealed the sensitivity of the EPR control loop and the dif ficulty in evaluating it. 8 The nozzle instability was encountered in the high-altitude, low-airspeed region of the flight envelope. The nozzle oscillated in a limit cycle with an amplitude of approxmately $0.4 \mathrm{ft}^{2}$ peak-to-peak at a frequency of approximately $1.5 \mathrm{~Hz}$. Some nozzle overshoots and undershoots also occurred during the augmentor sequencing. The instability resulted in augmentor blowouts, caused by the low pressure level that occurred when the nozzle was too far open, and stalls that occurred when the nozzle was too far closed, causing the fan back pressure to be too high. Figure 6 shows an example of a stall that occurred as a result of nozzle instability following an idle-to-maximum throttle transient at 175 knots and an altitude of $45,000 \mathrm{ft}$. The nozzle oscillation built up over a period of four cycles and the high pressure level back-pressured the fan, causing a stall. In other instances, the oscillation began, damped out, and began again, indicating a marginal stability in the nozzle control loop. The oscillation only occurred at augmented power, not at intermediate power. As shown in Fig. 4, the nozzle is controlled to maintain the desired engine pressure ratio (EPR). During the DEEC design and initial evaluation, the stability of the EPR control loop was evaluated and found to be adequate, based on simulation results. During ground tests to provide flight clearance at USAF Arnold Engineering and Development Center (AEDC), the EPR loop stability of the DEEC flight test engine was evaluated at low-airspeed and high-altitude conditions, but only at intermediate power. The nominal EPR loop gain was doubled and no instability was noted.

Because the altitude test results on the flight engine did not indicate a problem, the engine manufacturer's full, nonlinear, aerothermodynamic F100 engine simulation was used to investigate the instability. The simulation could not be made to duplicate the results observed in flight.

To more exhaustively investigate the causes of the EPR control loop nozzle instability, a study was conducted. 8 This study included an altitude test program, performed at the NASA Lewis Research Center. The F100 X0-11 engine used for this test did not exhibit any nozzle stability problens when operating with its normal control gain settings. A readily reprogrammable DEEC "breadboard" was used to provide variable gain and other control modifications. During the testing at Lewis, it was found that an increase in integral control gain could cause the nozzle to become oscillatory. Additional transfer function data for the EPR loop was also acquired before the tests were completed.

A nonlinear simulation of the EPR loop, incorporating the Lewis test results, was developed at
Ames-Dryden. A block diagram of the simulation is shown in Fig. 7. The dashed line on Fig. 4 encloses the functions modelled in the simulation. Significant nonlinearities included the deadband and sample and hold logic in the DEEC. Results of the Ames-Dryden nonl inear EPR loop simulation are shown in Fig. 8, for a Mach 0.6- and 45,000 ftflight condition. The simulation results in Fig. 8(a) show a limit cycle with very similar frequency and magnitude to the nozzle oscillation observed in flight. This nonlinear simulation, which incorporated the NASA Lewis test results, essentially duplicated the flight results, whereas the engine manufacturer's full nonlinear simulation, with less accurate data, did not predict the oscillation. This points out the importance of having high-quality engine modeling data.

Proposed logic changes for the DEEC software were evaluated on the Ames Dryden simulation. As shown in Fig. 8(b), when the deadband was increased, and the integral gain was cut in half, the response to the same step input in EPR request produced only a small overshoot that rapidly damped. This response was judged to be acceptable. These software changes were incorporated for the next phase of the DEEC flight evaluation, and flight results showed no evidence of nozzle instability. The lower EPR loop gains also reduced the number of nozzle overshoots that occurred during augmentor sequencing, and that reduced the number of blowouts that occurred during augmentor transients. The sensitivity of the EPR loop to system dynamics again points out the need for high-quality engine data in the engine simulation, the need to adequately model the nonlinearities, and the need to provide early flight tests of the engine.

Augmentor Rumble. Another anomaly was found in the DEEC augmentor testing. Rumble, a dynamic acoustic-combustion coupling phenomena, occurred in several instances. Rumble typically occurs when overrich mixtures are present at some region in the augmentor, at frequencies in the 50 to $100 \mathrm{~Hz}$ range. DEEC augmentor fuel schedules were developed based on testing at AEDC, including testing to determine the rumble margins. The tests on the flight engine at AEDC showed no rumble. However, during in-flight testing in the upper left-hand corner of the flight envelope, numerous blowouts occurred. Some were caused by the nozzle instability discussed in the previous section, but some were found to be caused by rumble. Figure 9 shows a time history of an idleto-maximum throttle transient at $40,000 \mathrm{ft}$ and an airspeed of 200 knots. Just as full augmentation was achieved, the augmentor pressure (PAB) showed a discrete pressure oscillation at a frequency of $60 \mathrm{~Hz}$ with an amplitude of approximately $2 \mathrm{lb} / \mathrm{in}^{2}$ (25 percent), which caused the blowout. Rumble was noted during several similar throttle transients. If the rumble was not severe enough to cause a blowout at this stage of the transient, the rumble died out within approximately $1 / 2 \mathrm{sec}$. It is believed that, during throttle transients, the pressure transients in the test cell at AEDC were not the same as those existing in flight. thus explaining the lack of rumble in the ADEC tests. The AEDC facilities are being modified to be capable of holding pressure more accurately. 
In later DEEC test phases, the augmentor fuel-air ratios were lowered slightly, and further tests were free of rumble.

As a result of the elimination of the nozzle instability and rumble, the augmentor operability was substantially improved. In the fourth DEEC test phase, idle-to-maximum throttle transients were conducted to the edge of the flight envelope, and all were successful, al though some PLA recycles were required. This provides an improvement in augmentor operation of over $11,000 \mathrm{ft}$.

Secondary Control Airstart Results. During the evaluation of the DEEC, the airstart capability of the SEC was evaluated, and unexpected hot starts occurred. The SEC airstart logic provides an open-loop preprogrammed schedule of fuel flow as a function of time. When the time elapses, the control switches to the schedules for normal operation. If the throttle is in the idle position when the timer elapses, fuel flow abruptly increases to the idle value, possibly resulting in stall and hot start. The flight results are compared to the AEDC test results in Fig. 10 and show that the successful airstart boundaries are significantly different. The difference was traced to the lack of horsepower extraction during the testing at AEDC. The horsepower extraction is considered small during normal engine operation, but during airstarts near the minimum afrspeed limits, the small horsepower extraction significantly slowed the rate of engine acceleration. AEDC test procedures were modified to properly simulate horsepower extraction during sensitive engine tests.

Summary of DEEC Results. The addition of the DEEC to the F100 engine produced a very 1 arge improvement in capability, in terms of operability, reliability and maintainability. The DEEC is now in production for the F100-PW-220 engine. The introduction into service was accelerated by approximately $11 / 2$ years as a result of the NASA $F-15$ test program.

\section{Fl00 EMO Control Results}

The F100 EMD engines were flown in the $F-15$ airulane to evaluate improvements in performance and operability. During this evaluation, the value of the F-15 for propulsion control research was again demonstrated.

Throttle Response. Throttle response of the F 100 EMD engine was evaluated for formation flying and derial refueling capability. 9 The flight condition of $10,000 \mathrm{ft}$ and 400 knots was selected to be representative of a tactical situation. The task was wing station keeping on the lead aircraft for perturbed and nonperturbed conditions and inodest manuevering. At this flight condition, station keeping for even nonperturbed tasks received a Cooper-Harper pilot rating of 6 to 8 (indicating improvement was required). A flight condition of $25,000 \mathrm{ft}$ and 300 knots was selected to be representative of aerial refueling. As shown in Fig. 11, large lags or delays were evident between throttle and thrust response. Thrust response had a phase $1 \mathrm{ag}$ in excess of $90 \mathrm{deg}$. The excessively slow response was caused by logic in the DEEC designed to increase the compressor stall margin during bodie throttle transients. This logic was incorporated without regard to its effect on thrust response. An additional factor was the lack of a quantitative criteria for throttle response. Once the problem became evident, a software change was incorporated into the DEEC, which improved the throttle response; subsequent Cooper-Harper ratings of 3 to 4 (indicating adequate response) were then obtained for the same flying tasks.

Compressor Stall Results. During F-15 flight testing, compressor stalls were encountered on the prototype configuration F100 EMD (PW1128) engine on intermediate-to-idle power throttle transients in the extreme upper left-hand corner of the flight envelope. These stalls were not predicted by previous altitude facility tests and could not be duplicated by additional altitude tests. The standard F100 engine, which has the same compressor as the F100 EMD, does not have a compressor stall problem anywhere in the envelope.

In an attempt to define the compressor stall problem, high-frequency response pressure probes were installed at the compressor inlet, and pressure data was recorded at 1000 samples per sec. During flights, the pressures near the inner diameter of the compressor inlet showed dynamic pressure fluctuations during throttle reductions. The flow dynamic characteristics were studied and appeared typical of separated flow, with no predominant frequencies present. The occurrence of the pressure dynamics was correlated as a function of the bypass ratio (the ratio of fan-to-core flow) and corrected compressor rpm, as shown in Fig. 12. During steady-state operation, the engine operates outside of the separated flow region, however, on throttle reductions, the engine control system allowed the engine to enter the separated flow region, and stalls occurred. This is shown in a cross-section of the engine, showing the flow through the three fan stages and the first compressor stage (Fig. 13). During a throttle reduction (Fig. 13(a)), the fan decelerates more slowly than the compressor, resulting in an increased bypass ratio and decreased compressor demand. This causes an adverse pressure gradient for the flow entering the compressor and increases the tendency toward flow separation. Conversely, on a throttle increase (Fig. 13(b)), the compressor speed increases more rapidly than the fan, decreasing the bypass ratio. This results in a higher compressor airflow demand and a favorable pressure gradient which tends to reattach the flow. At the very low pressures encountered during flight at low speed and high altitude, the separated flow entering the compressor could be sufficient to cause stall. Changes to the DEEC control schedules have since been made to keep engine operation outside of the separated flow region and, as shown in $\mathrm{Fig} .12$, no stalls have occurred. The control changes result in slower engine decelerations and slightly lower compressor efficiencies.

The value of the early flight evaluation was conclusively demonstrated when the fan diffuser flow separation problem was found early in the design cycle. Later versions of the F100 EMD, (currently designated PW1129) have a redesigned 
fan diffuser to el iminate the flow separation and the resulting performance penalties associated with the control system changes.

The reason the flight results could not be duplicated in the altitude test facilities is being studied. Tests were conducted at the NASA Lewis Research Center and at AEDC. Further tests will attempt to define the compressor inlet flow dynamics in more detail. It is possible that the ground facility flow dynamics are not quite the same as the dynamics occurring in flight. In any event, these results show the importance of engine control and the necessity of flight evaluation early in the development of engines.

\section{Adapt ive Engine Control System (ADECS) Evaluation}

As part of the highly integrated digital electronic control (HIOEC) program, an adaptive engine control system (ADECS) has been incorporated on the F-15 airplane. In ADECS (Fig. 14), airframe and engine information is used to allow the engine to operate at higher performance levels (uptrim) at times when the inlet distortion is low and the full engine stall margin is not required. The AOECS mode could al so be used to obtain additional engine stall margin (downtrim) during certain flight manuevers, such as a STOL landing rollout with reverse thrust where reingestion could cause an engine stall, or for extreme attitude flight, such as that which could be used in supermaneuverabllity concepts.

For the ADECS testing, the DEEC has been coupled to the digital electronic flight control system (DEFCS). A digital interface and bus control unit allows the various systems to communicate with each other. The HIDFC system is described in Ref. 4.

In a recent flight evaluation, the ADECS system was evaluated on one of the two F100 EMD engines on the F-15. Significant performance improvements were demonstrated. Thrust improvements and constant-thrust fuel flow reductions were determined and compared to predictions. The ability of the ADECS to adapt to rapid aircraft maneuvers and throttle transients was al so demonstrated. Intentional stalls were al so conducted to validate the stability audit procedures used to develop the ADECS logic.

Typical results are shown in Fig. 15 for an altitude of $30,000 \mathrm{ft}$. In Fig. 15(a) the calculated intermediate power thrust from the flight lata exceeds the predicted thrust, with increases of 8 to 10 percent. In Fig. 15(b), the fuel flow reductions obtained for the maximum nonuptrimmed thrust levels are shown; flight data matches predictions well, with decreases of 10 to 15 percent. These engine performance improvements resulted in airplane performance improvements of 5 to 13 percent, with the ADECS on only one engine.

Flight validation of the HIDEC ADECS mode has accelerated transfer of this technology to future advanced aircraft. The specifications for the advanced tactical fighter engines call for HIDEC capability to be provided.

\section{Concluding Remarks}

The NASA F - 15 research airplane has been shown to be an effective flight test vehicle for early evaluation and demonstration of advanced propulsion control concepts.

The DEEC system encountered several development problems in an early flight evaluation which had not been predicted from analys is and ground test. These problems were found and solved in a timely and cost-effective manner. The DEEC improves augmentor operability, eliminates trimming, and has greatly improved the engine reliability and maintainability. The DEEC system is now in production. The early flight evaluation of the F100 EMD was also quite useful. In F100 EMD tests, unexpected problems were encountered inflight, including a throttle response problem and a compressor stall problem, both of which were solved with control system changes. More recently, the HIDEC flight tests of an adaptive engine control system have validated integrated propulsion-flight control concepts which are now being specified for future advanced aircraft.

\section{References}

lBurcham, Frank W. Jr., Trippensee, Gary A., Fisher, David F., and Putnam, Terrill W. " Summary of Results of NASA F-15 Flight Research Program." A IAA-86-9761, Apr. 1986.

2Burcham, F.W., Myers, L.P., and Walsh, K.R., "Flight Evaluation of a Digital Electronic Engine Control in an F-15 Airplane," J. Aircraft, vol. 22, no. 12, Dec. 1985, pp. $1072-1078$.

3Myers, Lawrence P., and Burcham, Frank W., Jr., "Prel iminary Flight Test Results of the F100 EMD' Engine in an F-15 Airplane," AIAA-84-1332, June 1984. (Al so published as NASA TM-85902, 1984.)

4Putnam, Terrill W., Burcham, Frank W., Jr., Andries, Mary G., and Kelly, James B., "Performance Improvements of a Highly Integrated Digital Electronic Control System for an F-15 Airplane," AIAA-85-1876, Aug. 1985. (A) so published as NASA TM $-86748,1985$.)

5 Baer-Riedhart, Jennifer L., "Digital Electronic Engine Control Fault Detection and Accommodation Flight Evaluation," Digital Electronic Engine Control (DEEC) Flight Evaluation in an F-15 Airplane, NASA CP-2298, 1984, pp. 107-126.

6Johnson, J. Blair and Nelson, Jeff, "Flight Evaluation of the DEEC Secondary Engine Control Air-Start Capability," NASA TM-84910, 1983.

7Myers, Lawrence P., Baer-Riedhart, Jennifer L., and Maxwell, Michael D., "Fault Detection and Accormodation Testing on an F100 Engine in an F-15 Airplane," AIAA-85-1294, July 1985. (Al so published as NASA TM-86735, 1985.)

BBurcham, F.W., Jr., Myers, L.P., and Zeller, J.R., "Flight Evaluation of Modifications to a Digital Electronic Engine Control System in an F-15 Airplane," AIAA 83-0537, Jan. 1983. (Al so published as NASA TM-83088, 1983.) 

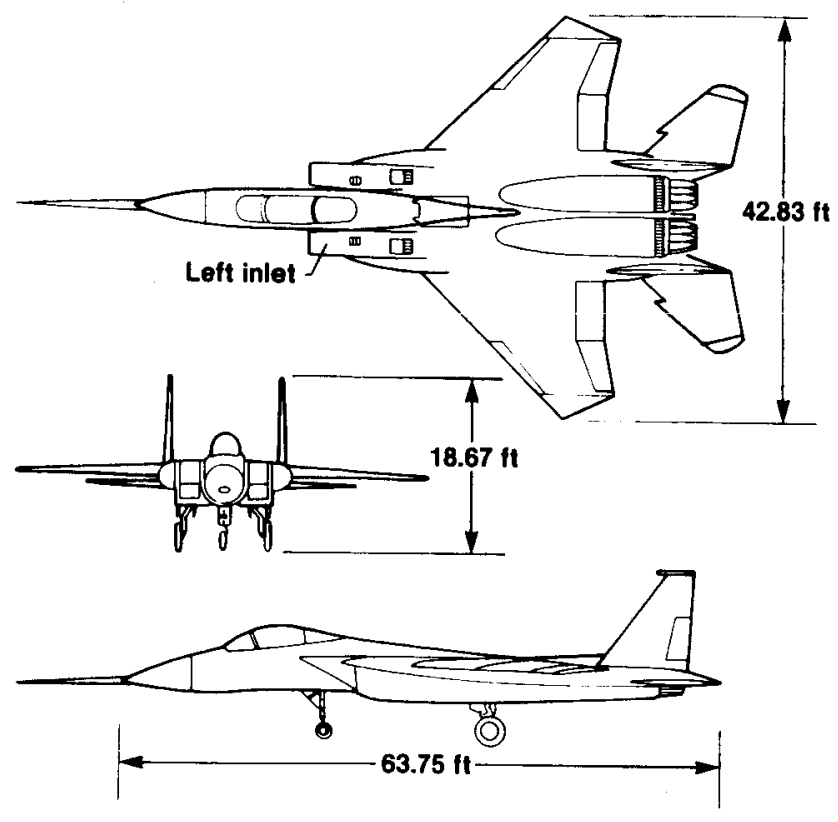

Fig. 1 Three-view of test airplane.

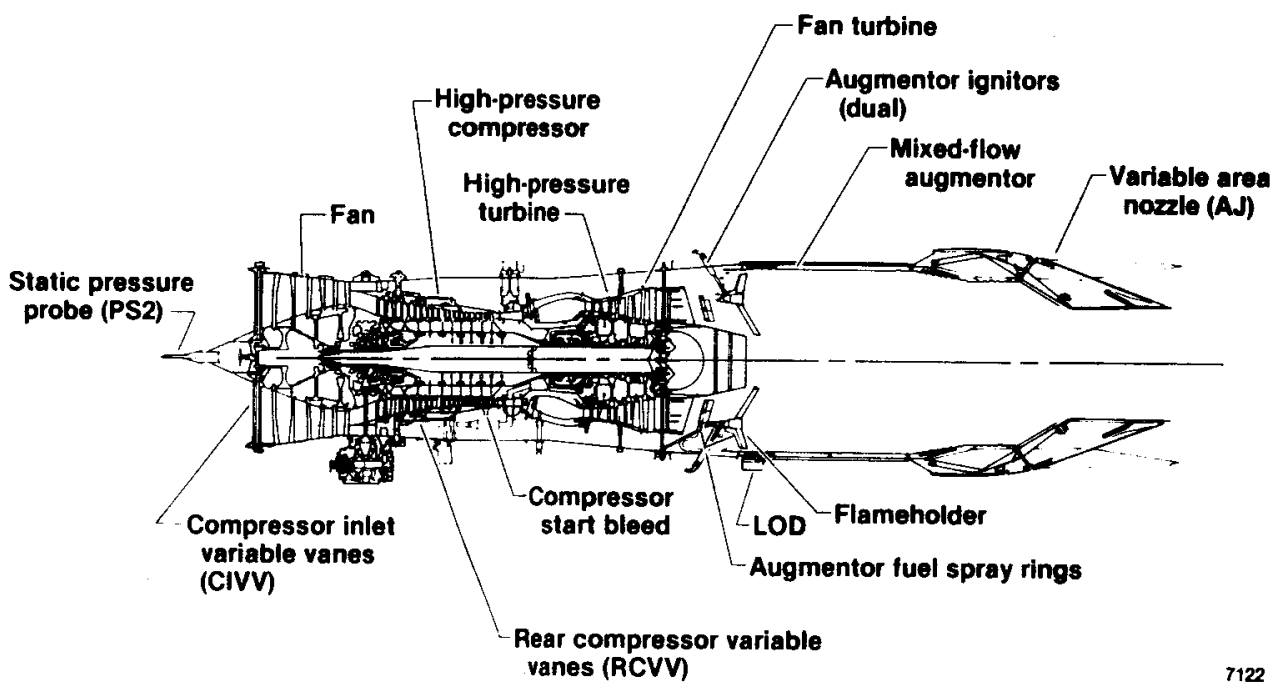

Fig. 2 Section view of the F100 engine. 


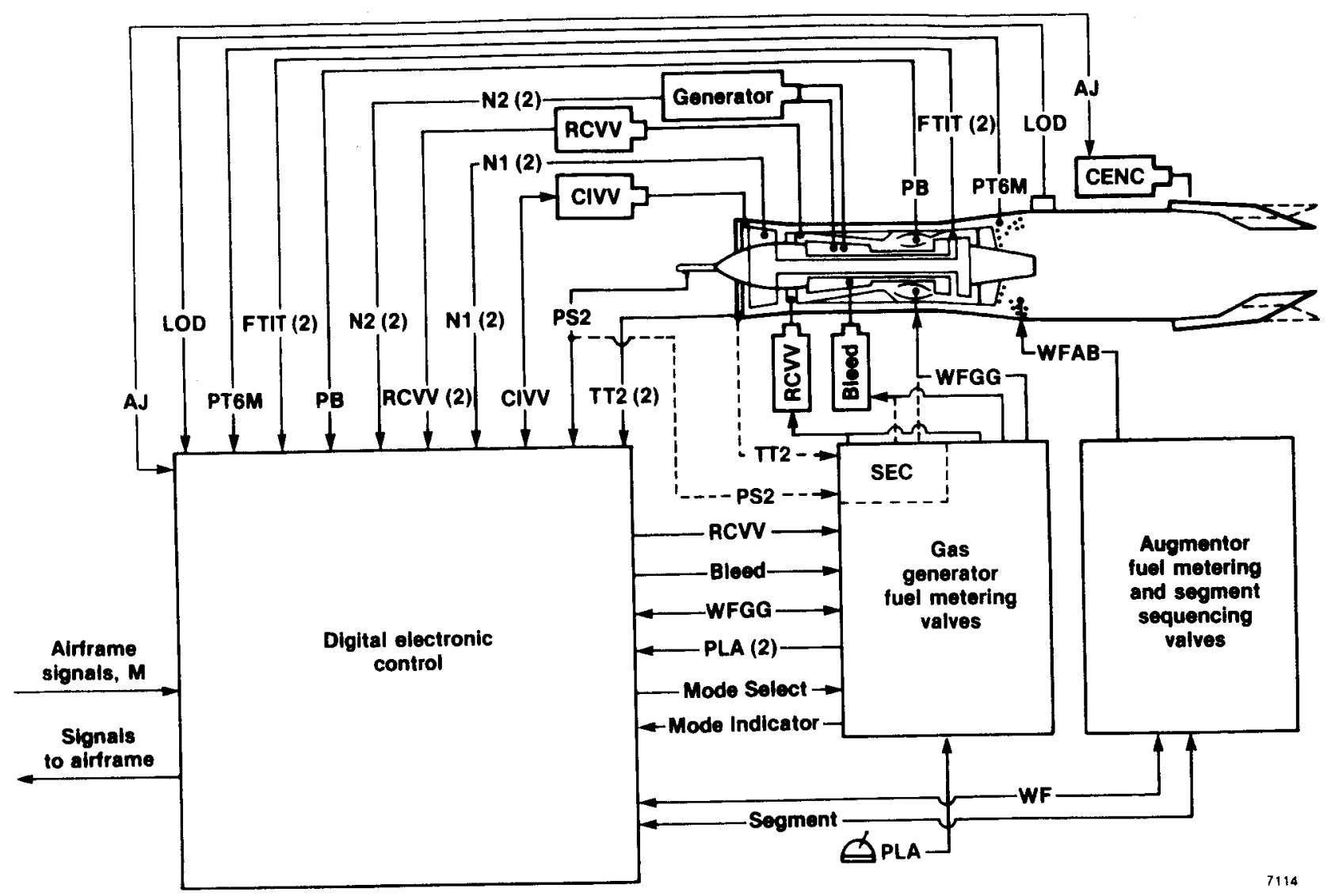

Fig. 3 DEEC system used for F100 BMD tests.

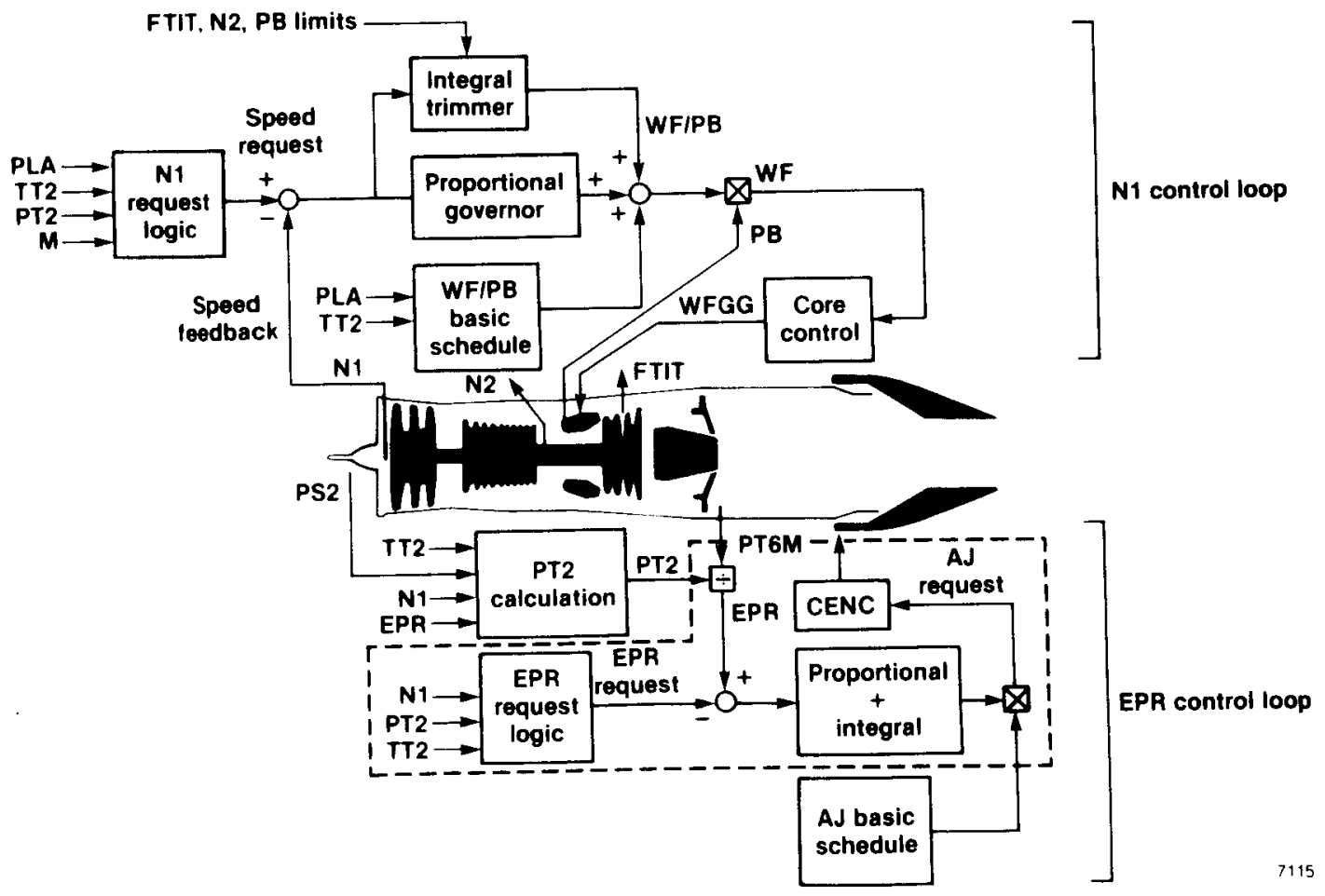

Fig. 4 The DEEC modes for fan rotor speed and engine pressure ratio. 
Sensor fallures

O Steady-state power

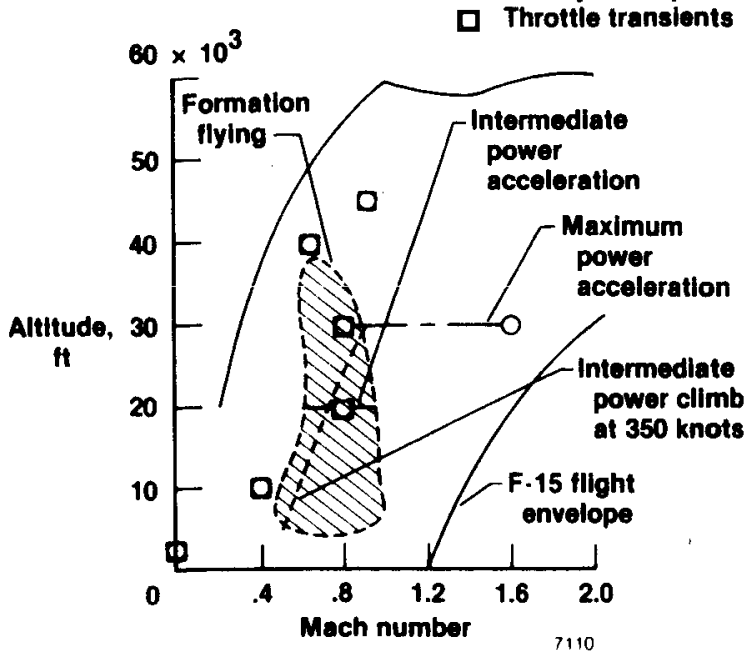

Fig. 5 DEEC - FDA test points.

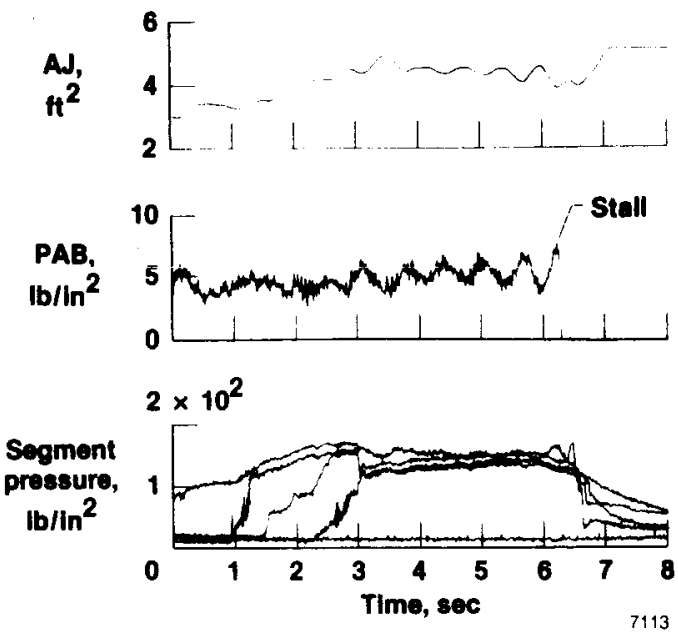

Fig. 6 Time history of an idle-tomaximum power throttle transient in which nosste instability caneed a stall. $V C=175$ knots, $H P=45,000 \mathrm{ft}$.

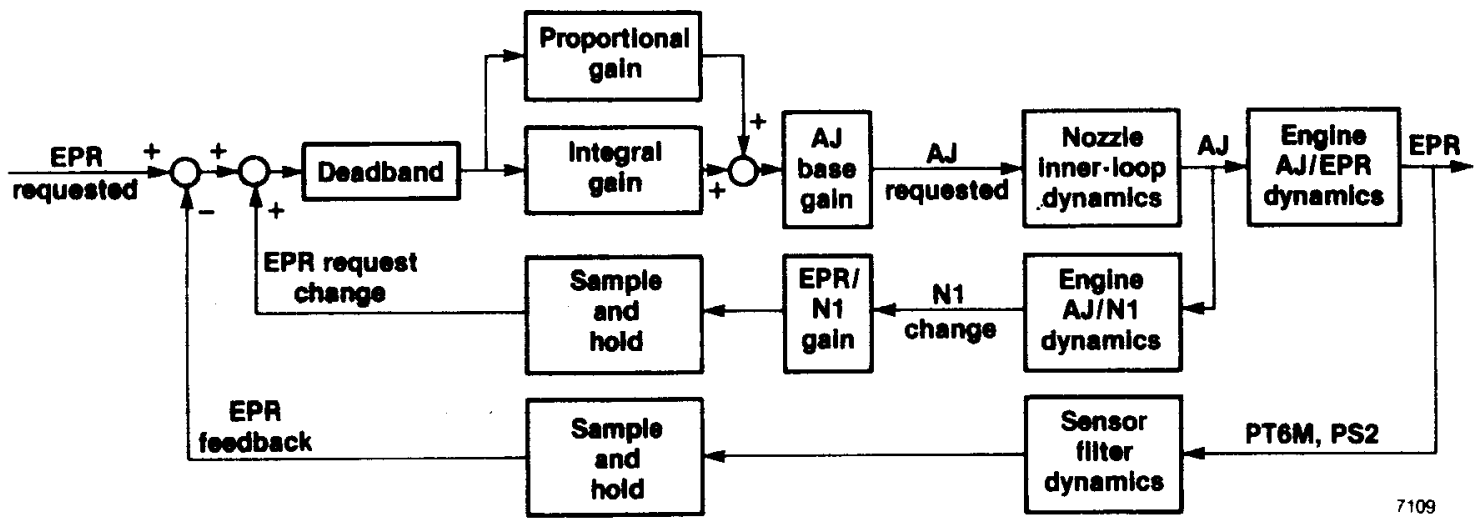

Fig. ? Block diagram of the DEEC nonlinear noszle simulation.

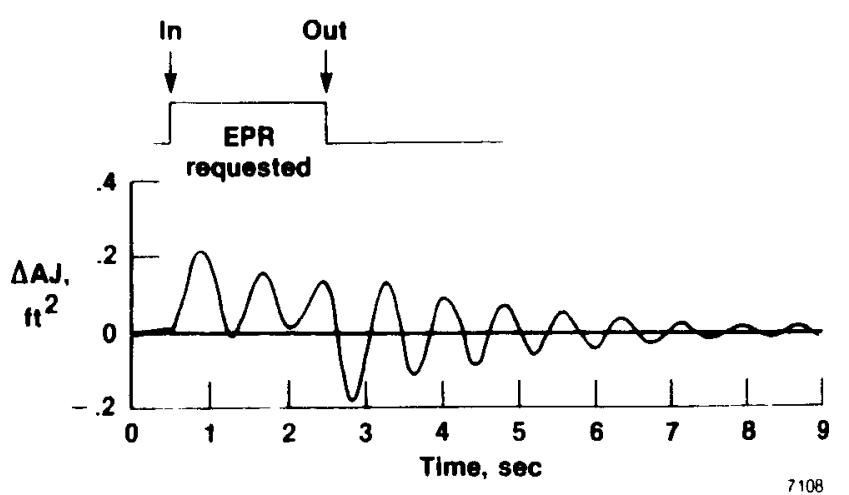

(a) Phase 2 control logic.

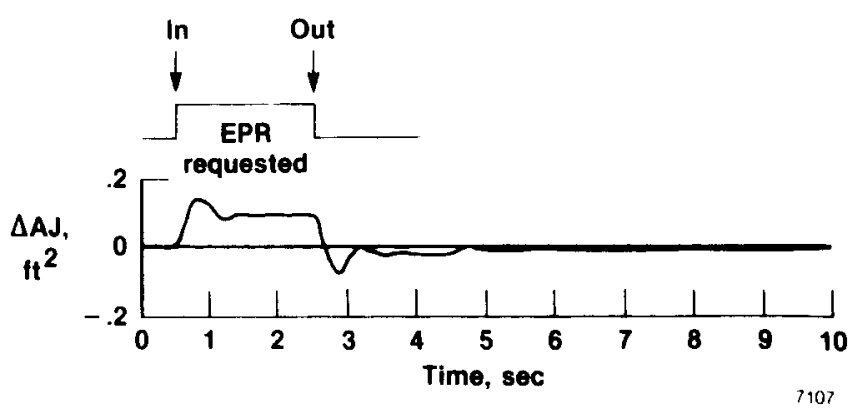

(b) Phase 3 control logic.

Fig. 8 DEEC nonlinear nossle simulation results. $M=0.6, H P=45,000 \mathrm{ft}$. 

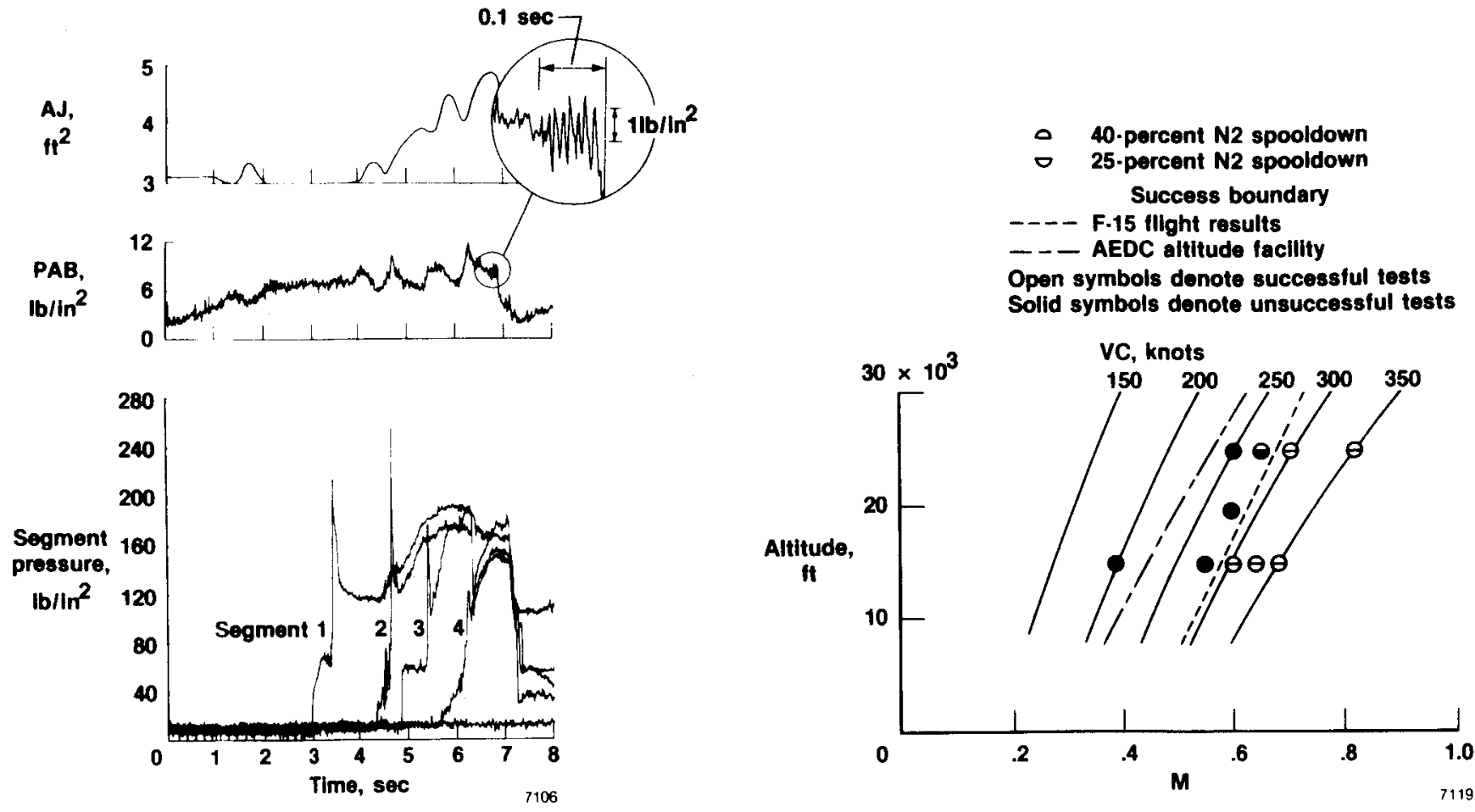

Fig. 9 Time history of a rumble blowout during an idle-maximum throttle transient, $H P=$ $40,000 \mathrm{ft}, V C=200$ knots.

Fig. 10 Summary of initial SBC-mode air starts and success boundaries.
-40 -percent N2 spooldown
$-\quad 25$-percent N2 spooldown

Success boundary

- - F.15 flight results

- - AEDC altitude facllity

Open symbols denote successful tests

Solid symbols denote unsuccessful tests 


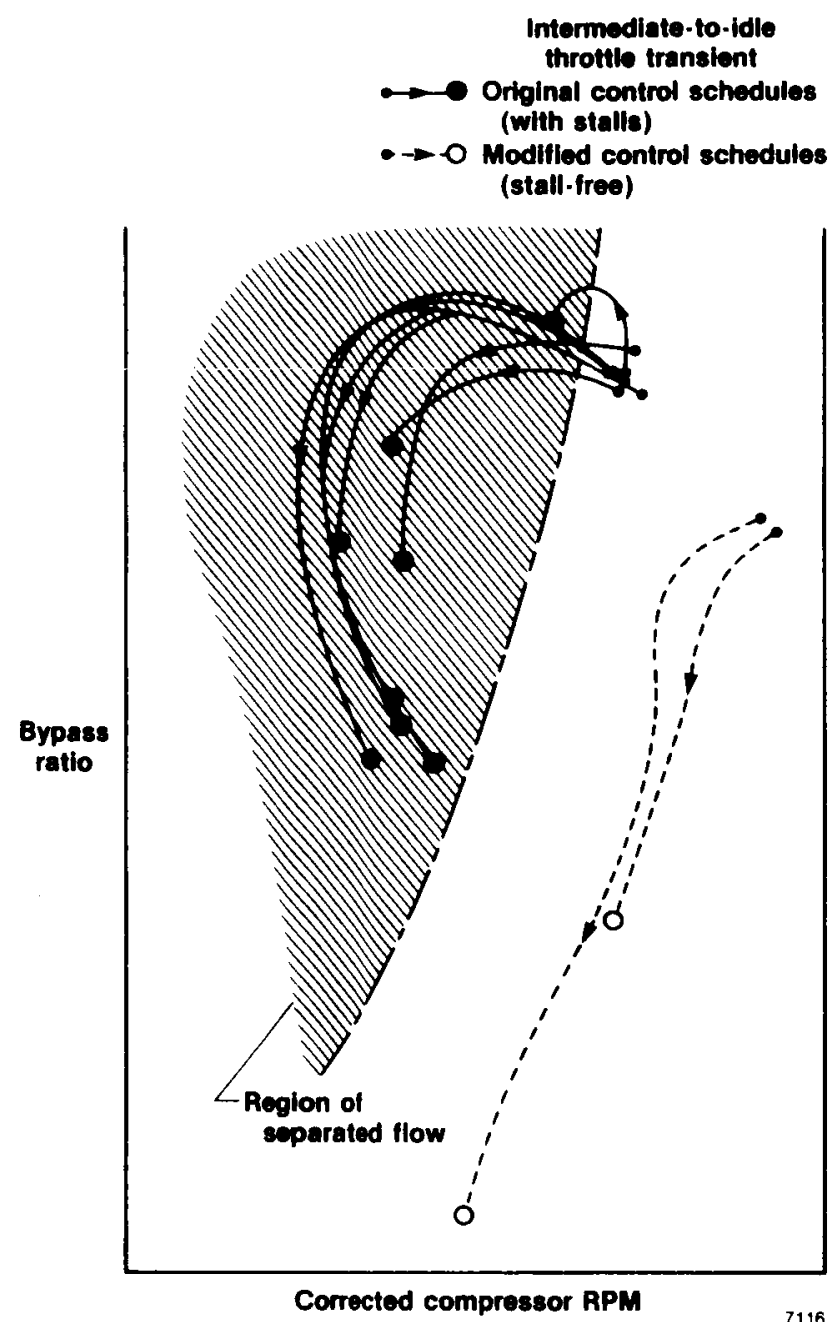

Fig. 12 Comparison of flight results for throttle reductions, with original and modified control schedule.

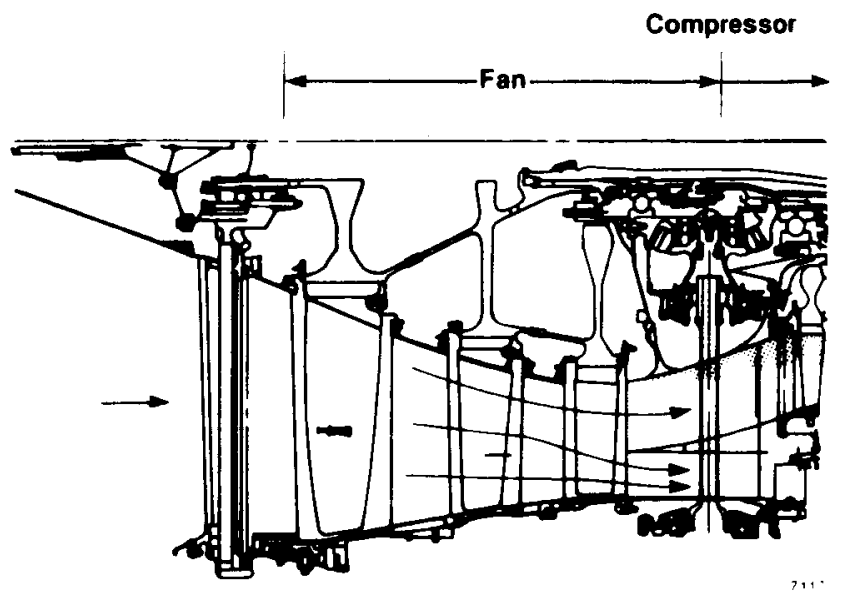

(a) Throttle recuction (with separation).

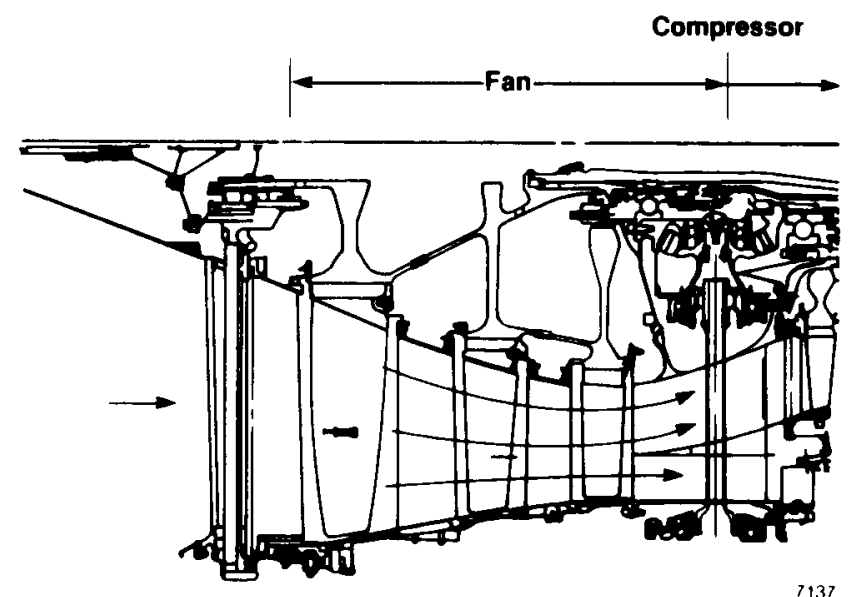

(b) Throttle inorease.

Fig. 13 F100 BMD fan-compress or flow. 


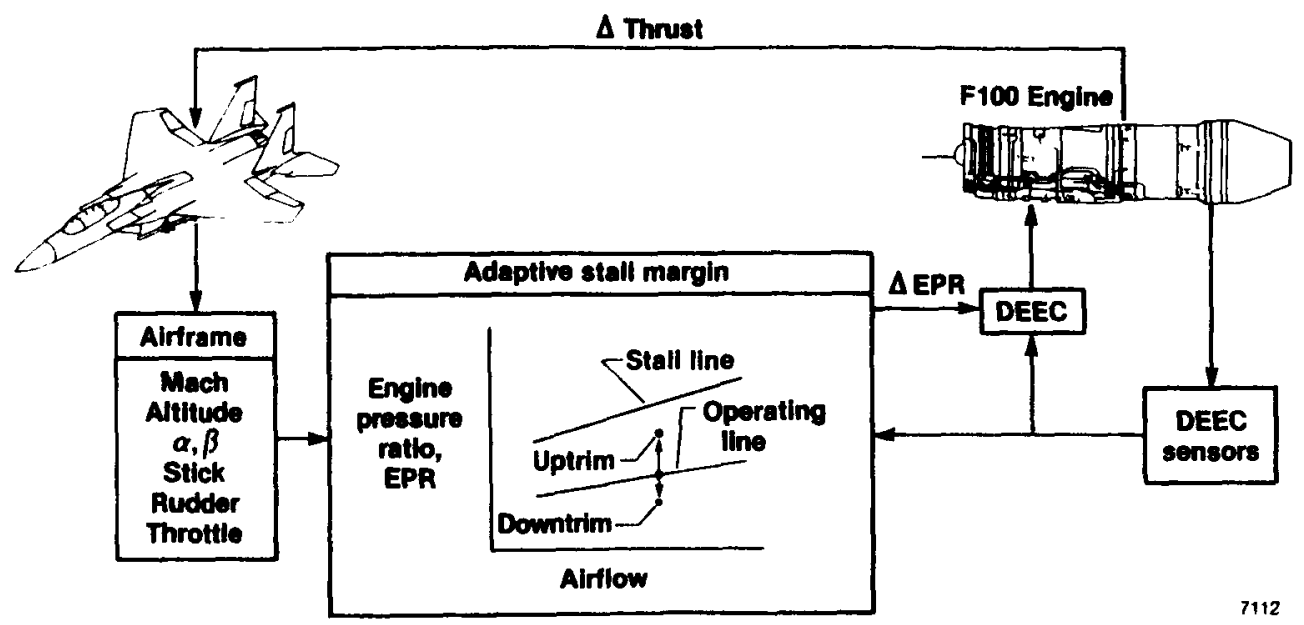

Fig. 14 Block diagram of the HIDBC adaptive engine control system.

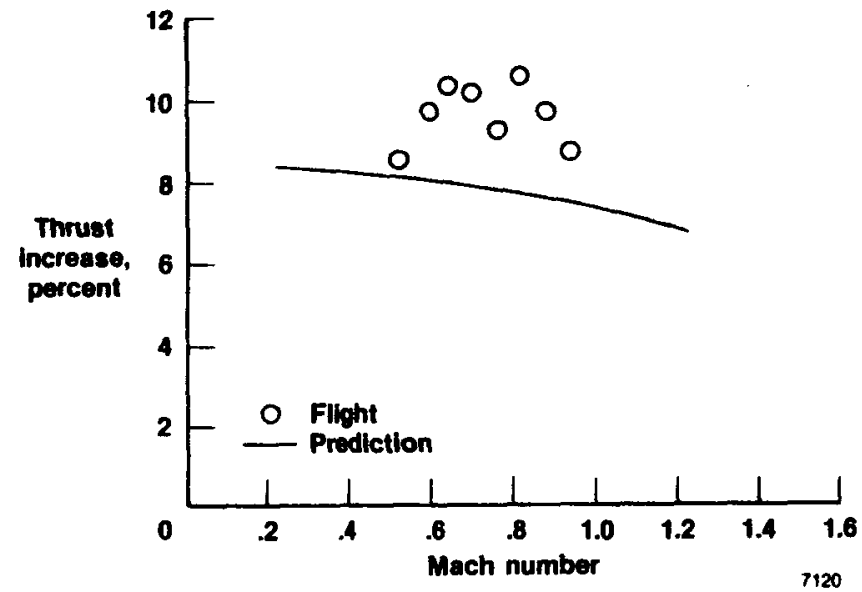

(a) Thrust increase for ADECS mode at intermediate power.

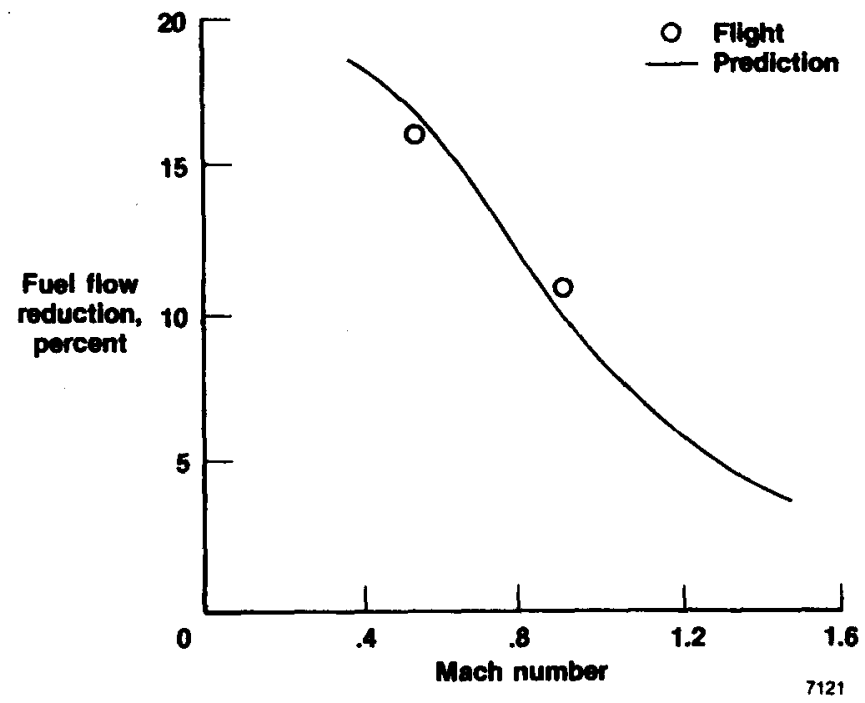

(b) Rechotion in fuel flow with uptrim to obtain noruptrimmed maximum thrust.

Fig. 15 Compario on of ADBCS flight results and predictions. 


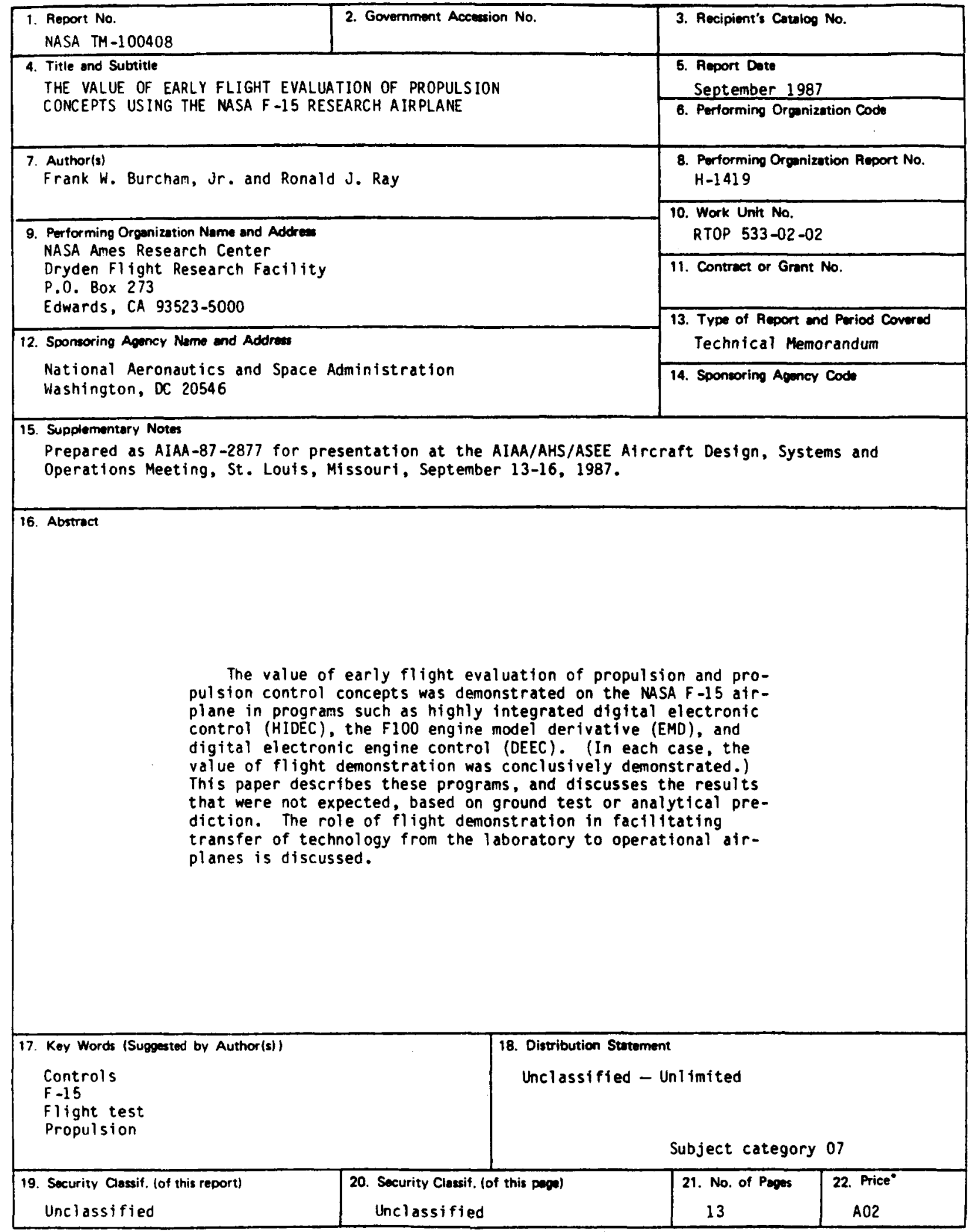

"For sale by the National Technical Information Service, Springfield, Virginia 28101. 